\title{
MHC Universal Cells Survive in an Allogeneic Environment after Incompatible Transplantation
}

\author{
Constança Figueiredo, ${ }^{1}$ Dirk Wedekind, ${ }^{2}$ Thomas Müller, ${ }^{1}$ Stefanie Vahlsing, \\ Peter A. Horn, ${ }^{3}$ Axel Seltsam, ${ }^{1,4}$ and Rainer Blasczyk ${ }^{1}$ \\ ${ }^{1}$ Institute for Transfusion Medicine, Hannover Medical School, Lower Saxony, 30625 Hannover, Germany \\ ${ }^{2}$ Institute for Laboratory Animal Science, Hannover Medical School, Lower Saxony, 30625 Hannover, Germany \\ ${ }^{3}$ Institute for Transfusion Medicine, University Hospital Essen, 45147 Essen, Nordrhein-Westfalen, Germany \\ ${ }^{4}$ German Red Cross, Blood Services NSTOB, Institute Springe, Lower Saxony, 31832 Springe, Germany
}

Correspondence should be addressed to Constança Figueiredo; figueiredo.constanca@mh-hannover.de

Received 10 June 2013; Revised 29 August 2013; Accepted 29 August 2013

Academic Editor: Chung-Liang Chien

Copyright (C) 2013 Constança Figueiredo et al. This is an open access article distributed under the Creative Commons Attribution License, which permits unrestricted use, distribution, and reproduction in any medium, provided the original work is properly cited.

Cell, tissue, and organ transplants are commonly performed for the treatment of different diseases. However, major histocompatibility complex (MHC) diversity often prevents complete donor-recipient matching, resulting in graft rejection. This study evaluates in a preclinical model the capacity of MHC class I-silenced cells to engraft and grow upon allogeneic transplantation. Short hairpin RNA targeting $\beta 2$-microglobulin (RN_sh $\beta 2 \mathrm{~m}$ ) was delivered into fibroblasts derived from LEW/Ztm $\left(\mathrm{RT}^{1}{ }^{1}\right)\left(\mathrm{RT} 1-\mathrm{A}^{\mathrm{l}}\right)$ rats using a lentiviral-based vector. MHC class I (RT1-A-) expressing and -silenced cells were injected subcutaneously in LEW rats (RT1 ${ }^{1}$ ) and MHC-congenic LEW.1W rats $\left(\mathrm{RT}^{\mathrm{u}}\right)$, respectively. Cell engraftment and the status of the immune response were monitored for eight weeks after transplantation. In contrast to RT1-A-expressing cells, RT1-A-silenced fibroblasts became engrafted and were still detectable eight weeks after allogeneic transplantation. Plasma levels of proinflammatory cytokines IL- $1 \alpha$, IL- $1 \beta$, IL- 6 , TNF- $\alpha$, and IFN- $\gamma$ were significantly higher in animals transplanted with RT1-A-expressing cells than in those receiving RT1-A-silenced cells. Furthermore, alloantigen-specific T-cell proliferation rates derived from rats receiving RT1-A-expressing cells were higher than those in rats transplanted with RT1-A-silenced cells. These data suggest that silencing MHC class I expression might overcome the histocompatibility barrier, potentially opening up new avenues in the field of cell transplantation and regenerative medicine.

\section{Introduction}

Regenerative medicine is a new field of research emerging in response to the shortage of organs, tissues, and cells for transplantation and treatment of degenerative diseases [1]. However, the development of therapeutic approaches in this field is often based on the use of allogeneic products. Immunogenicity is a major obstacle to the successful use of these products for allogeneic transplantation. Even autologous cells-either genetically modified adult cells or induced pluripotent stem (iPS) cells-are targeted by the immune system after transplantation. The major histocompatibility complex (MHC) is the most relevant genomic region responsible for transplant rejection. Human MHC proteins are referred to as human leukocyte antigens (HLA) because they were first discovered on leukocytes. HLA compatibility plays a pivotal role in the success of allogeneic transplantation, and the number of donor-recipient HLA mismatches is associated with the severity of graft rejection and the transplant survival rate $[2-5]$.

A continuously growing number of new HLA alleles have been identified by molecular genetic analysis in the last two decades, reflecting the great diversity of the HLA loci. Because an extremely large pool of donors is needed to find an unrelated HLA-matched donor for a given individual, it is usually impossible to find a complete HLA-matched donor, especially for patients with rare HLA alleles. Improvements in immunosuppressive therapy have reduced the degree of T-cell-mediated immune response to grafts, resulting in an increase in overall graft survival and a decrease in acute 
rejection [6-8]. Nonetheless, rejection due to antibodymediated graft injury resulting from B-cell responses to mismatched human HLA antigens remains a severe problem. Anti-HLA class I antibodies are involved in acute rejection, whereas anti-HLA class II antibodies are of major importance in late rejection. HLA-A, HLA-B, and HLA-DR compatibility is therefore essential to reduce the number of mismatched $\mathrm{T}$ and B-cell determinants. Furthermore, long-term immunosuppression increases the patient's susceptibility to cancer and opportunistic infections [9-11].

RNA interference (RNAi) is now commonly used to investigate cellular or molecular mechanisms, and the pharmaceutical industry has recognized RNAi as a powerful therapeutic tool for the treatment of both viral infections and diseases caused by the abnormal expression of certain genes [12]. RNAi is a process whereby double-stranded RNA induces sequence-specific degradation of homologous mRNA [13]. The main diseases treated using RNAi gene therapy include hepatitis B, human immunodeficiency virus (HIV) infection $[14]$, cancer $[15,16]$, neurodegenerative disorders [17], ocular diseases [18], respiratory diseases [19], and arthritis [20]. We have previously described the feasibility of silence HLA class I and class II expression using RNAi technology [21-23]. In addition, other groups have knockedout the expression of HLA class I using Zink-finger nucleases. Furthermore, we and others have shown the feasibility to generate HLA universal (HLA-silenced) cells derived from CD34+ progenitor cells, iPS and ESCs [24]. However, the capacity of HLAsilenced cells to escape the allogeneic immune response was only tested in vitro. In this study, we evaluate the capacity of HLA universal cells to survive in a fully allogeneic environment in a rat transplantation model. Rat models are the most widely used experimental transplantation models. As in humans, MHC known as the RT1 complex regulates immune responses to natural proteins. Human MHC class I molecules are highly homologous to rat MHC class I molecules, which are designated RT1-A and RT1-C/-E/-M. Several haplotypes have been detected within the RT1-A region [25]. Therefore we have selected this animal model to investigate whether HLA-silenced adult cells have a superior capacity to prevent and escape the allogeneic immune response.

\section{Material and Methods}

2.1. Experimental Animals. Inbred (LEW) and coisogenic inbred (LEW.1W) rats differ only in their MHC haplotype (RT1': RT1-A ${ }^{1}$, RT1-B/D ${ }^{1}, \mathrm{RT}_{1} \mathrm{C}^{\mathrm{l}}$ versus RT1 ${ }^{\mathrm{u}}$ : RT1-A ${ }^{\mathrm{u}}$, RT1$\mathrm{B} / \mathrm{D}^{\mathrm{u}}$, and $\left.\mathrm{RT} 1-\mathrm{C}^{\mathrm{u}}\right)$. All strains used at our facility are regularly subjected to genetic testing in order to exclude the possibility of genetic contamination and to verify the authenticity of the strains. The LEW and LEW.1W rats were maintained in a minimally sustained facility that is regularly monitored for murine pathogens according to FELASA recommendations. Both strains were kept under identical conditions with $10: 14 \mathrm{~h}$ light-dark cycles in type IV Macrolon cages with free access to water and sterilized standard laboratory chow (Diet number 1324, Altromin, Detmold, Germany).
Appropriate ethical and regulatory approval for use of the animals and animal-derived tissues was obtained.

2.2. Short Hairpin RNA Design and Vector Production. Regions sensitive for short hairpin RNA (shRNA) were identified on $\beta 2$-microglobulin $(\beta 2 \mathrm{~m})$ transcripts from brown rats (Rattus norvegicus). shRNA sequences silencing $\beta 2 \mathrm{~m}$ expression were designed using a web-based algorithm (siRNA Target finder; http://www.ambion.com/). pLVTHM, psPAX2, and pMD2G vectors were kindly provided by Didier Trono of Geneva, Switzerland. Oligonucleotides containing the selected shRNA sequences were cloned into PLVTHM. RT1 cells showing a reduction by up to $70 \%$ in RT1-A protein expression in comparison to the cells transduced with a vector encoding for a control shRNA (shNS) were produced by the delivery of shRNA_1. A reduction higher than $70 \%$ was achieved by the delivery of shRNA_2. This shRNA_2 sequence was selected to produce the cell line for the transplantation experiments described in this study and received the name RN_sh $\beta 2 \mathrm{~m}$ (See Supplementary Material available online at http://dx.doi.org/10.1155/2013/796046).

Lentiviral particles were produced by transfecting $5 \times 10^{6}$ human embryonic kidney (HEK)293T cells using Lipofectamine 2000 (Invitrogen, Carlsbad, CA) according to the manufacturer's instructions. Transfection was performed using $9 \mu \mathrm{g}$ of psPAX2 (plasmid containing the gag and pol genes and encoding the structural proteins and the reverse transcriptase), $3 \mu \mathrm{g}$ of pMD2G (plasmid encoding vesicular stomatitis virus $\mathrm{G}$ envelope protein), and $10 \mu \mathrm{g}$ of pLVTHM (plasmid encoding the shRNA sequences). After 16 hours of transfection, the cells were washed and incubated with complete Dulbecco's Modified Eagle's Medium (DMEM, LONZA, Verviers, Belgium) supplemented with 10\% (vol/vol) fetal calf serum (FCS) and $1 \%$ (vol/vol) glutamine. Virus supernatants were collected 48 hours after transfection and passed through a $0.45 \mathrm{~mm}$ filter (Millipore, Billerica, MA). Virus supernatants were concentrated overnight by centrifugation at $12000 \mathrm{~g}$ and $4^{\circ} \mathrm{C}$.

2.3. Cell Culture. A LEW fibrosarcoma cell line (RT1, ECACC 94011416) was stably transfected with pcDNA3.1-V5/His (Invitrogen, Groningen, The Netherlands), a plasmid-based vector encoding for the firefly luciferase gene sequence, and cultured in Eagle's Minimum Essential Medium (LONZA, Verviers, Belgium) supplemented with $2 \mathrm{mM}$ glutamine (C.C. Pro, Neustadt, Germany), 1\% (vol/vol) nonessential amino acids (Invitrogen/GIBCO, Auckland, New Zealand), and $5 \%$ (vol/vol) FCS (LONZA). HEK cells were cultured in DMEM (LONZA) supplemented with $2 \mathrm{mM}$ glutamine (C.C. Pro, Neustadt, Germany), 1\% (vol/vol) nonessential amino acids (Invitrogen/GIBCO, Auckland, New Zealand), and 10\% (vol/vol) FCS (LONZA).

2.4. Cell Transduction. RT1 fibrosarcoma cells $\left(1 \times 10^{6}\right)$ were resuspended in $1 \mathrm{~mL}$ of concentrated viral supernatant and plated on six-well dishes. Cell transduction was performed in the presence of $8 \mathrm{mg} / \mathrm{mL}$ protamine sulfate (SigmaAldrich) at $37^{\circ} \mathrm{C}$ for 8 hours, after which the cells were 
supplied with fresh medium. On day 4, RT1-A expression was evaluated by flow cytometry after staining with a phycoerythrin- (PE-) labeled mouse anti-rat RT1-A antibody (BD Bioscience, Erembodegem, Belgium). PE-conjugated mouse immunoglobulin (Ig)G antibody (BD Bioscience) was utilized for isotype control. $\beta 2 \mathrm{~m}$ transcript levels were determined by real-time polymerase chain reaction (PCR) on days 4,8 , and 30 .

2.5. Real-Time PCR. Total RNA from transduced and nontransduced fibroblasts was isolated 4 days after transduction or immediately before cell transplantation and used in reverse transcription reactions to cDNA (High Capacity cDNA Reverse Transcription Kit, Applied Biosystems, Foster City, CA). Fifty nanograms of total RNA were used in each reverse transcription reaction. $\beta 2$-microglobulin and $\beta$-actin RNA levels were determined by two-step real-time PCR (TaqMan Gene Expression Master Mix, Applied Biosystems) using amplification primers and FAM-labeled TaqMan minor groove-binding probes for $\beta 2$-microglobulin $\left(5^{\prime}\right.$-GCCATCCACCGGAGAATG- $3^{\prime}$ and $5^{\prime}$-GGTGGAACTGAGACACGTAGCA- $3^{\prime} ; 5^{\prime}$-FAM-AAGCCCAACTTCC- $3^{\prime}$ ) and $\beta$ actin $\left(5^{\prime}\right.$-TTCAACACCCCAGCCATGT- $3^{\prime}$ and $5^{\prime}$-CAGAGGCATACAGGGACAACAC- $3^{\prime} ; 5^{\prime}$-FAM-CGTAGCCATCCAGGC- $3^{\prime}$ ). The constitutively expressed $\beta$-actin gene was used as the control for normalization of CDNA levels. Thermal cycling was performed on a commercially available real-time PCR system (StepOne Plus, Applied Biosystems) at $95^{\circ} \mathrm{C}$ for 10 minutes followed by 40 cycles at $95^{\circ} \mathrm{C}$ for 15 seconds and $60^{\circ} \mathrm{C}$ for 1 minute.

2.6. Cell Transplantation. LEW rat-derived fibrosarcoma cells were transplanted into LEW rats (syngeneic transplantation) or LEW.1W rats (allogeneic transplantation), respectively. One million fibrosarcoma cells were injected subcutaneously in the left hind leg of each animal. Groups of eight animals each received either RT1-A-expressing or RT1A-silenced fibrosarcoma cells.

2.7. Evaluation of Tumor Growth by Palpation and Collection of Tumor Cells after Transplantation. After cell transplantation, tumor formation and growth were monitored weekly by palpation and measured weekly using a vernier caliper. Tumor volume $(V)$ was calculated using the formula $V=$ $\pi$.ri.ro.h. In addition, a tumor biopsy was performed at week 2 after transplantation, and samples of tumor cells were collected at the time sacrificing the animals (week 8).

2.8. In Vivo Bioluminescence Imaging. The rats were anesthetized with ketamine $(100 \mathrm{mg} / \mathrm{kg}$ intraperitoneally) and xylazine $(10 \mathrm{mg} / \mathrm{kg} 226$ intraperitoneally), and an aqueous solution of D-luciferin $(150 \mathrm{mg} / \mathrm{kg})$ was injected subcutaneously 5 minutes before bioluminescence imaging. The animals were then placed in a dark chamber of the chargecoupled device camera (IVIS200, Xenogen, Cranbury, NJ, USA), and grayscale body surface reference images (digital photographs) were taken under weak illumination. The light source was switched off, and photons emitted from luciferase-expressing cells within the body and transmitted through the rat tissues were quantified over defined times of up to 5 minutes using Living Image software (Xenogen Biosciences, Cranbury, NJ) as an overlay on Igor Pro (WaveMetrics, Seattle, WA, USA). For anatomical localization, a pseudocolor image representing light intensity (blue, least intense; red, most intense) was generated in Living Image and superimposed over the grayscale reference image. Quantified luminescence consists of averaged photon radiance on the body surface and is expressed as photons $/ \mathrm{sec} / \mathrm{cm}^{2} / \mathrm{sr}$ where sr: steradian.

2.9. Immunohistochemistry Analysis. Tissue generated by growing RT1-A-expressing and RT1A-silenced cells was obtained during pathological analysis and immediately fixed in $4 \%$ paraformaldehyde for $48 \mathrm{~h}$, washed twice in phosphatebuffered saline (PBS), embedded in paraffin, and mounted on SuperFrost slides. Embedded tissue sections were incubated in histolene for $10 \mathrm{~min}$ to remove the paraffin, rehydrated in decreasing concentrations of alcohol $(100,90,80,70$, and $50 \%$ ethanol for $10 \mathrm{~min}$ each), and finally treated with $\mathrm{dH}_{2} \mathrm{O}$ for $10 \mathrm{~min}$. Staining was performed according to the DAKOLSAB System HRB procedure. Primary antibodies were used according to the manufacturer's recommendations $(1: 100)$, and peroxidase block was applied for $10 \mathrm{~min}$. Slides were blocked for $1 \mathrm{~h}$ at room temperature with $5 \%$ donkey serum, phosphate-buffered saline, $0.1 \%$ bovine serum albumen (BSA), and $0.1 \%$ Triton-X-100 and drained and incubated overnight with primary rat natural killer (NK) cell-specific antibody (kindly provided by Dr. Joachim Hundrieser, Center of Surgery, Hannover Medical School) at $4^{\circ} \mathrm{C}$ in the presence of $1 \%$ BSA. Slides were rinsed $2 \times 5 \mathrm{~min}$ with Tris-buffered saline (TBS) $+0.1 \%$ Triton and horseradish peroxidase-conjugated antibodies were added 1:200 to TBS $+1 \% \mathrm{BSA}$ for $1 \mathrm{~h}$ at room temperature. After three washing steps in PBS, the sections were embedded in Mowiol/DABCO and analyzed. Pictures were taken with a Biozero BZ-8000 fluorescence microscope (Keyence $\mathrm{GmbH}$, Neu-Isenburg, Germany).

2.10. T-Cell Isolation. Peripheral blood samples were collected from the rat donors after transplantation of RT1A-expressing and -silenced fibrosarcoma cells. Peripheral blood mononuclear cells obtained from these donors were separated by Lymphosep (C.C. Pro) gradient centrifugation followed by T-cell isolation (anti-T-cell OX52 isolation kit, Miltenyi Biotec, Bergisch Gladbach, Germany). T-cell purity was confirmed by flow cytometry using a PE-conjugated antiCD3 antibody (BD Bioscience).

2.11. In Vitro T-Cell Proliferation Assays. T cells derived from LEW and LEW.1W rats transplanted with RT1-A-expressing or -silenced fibrosarcoma cells were labeled with carboxyfluorescein succinimidyl ester (CFSE) as previously described [26]. One hundred thousand CFSE-labeled T cells were cocultured with $20 \times 10^{4}$ irradiated RT1-A-expressing fibrosarcoma cells in a 96-well plate for 8 days. T-cell proliferation was analyzed by flow cytometry. 


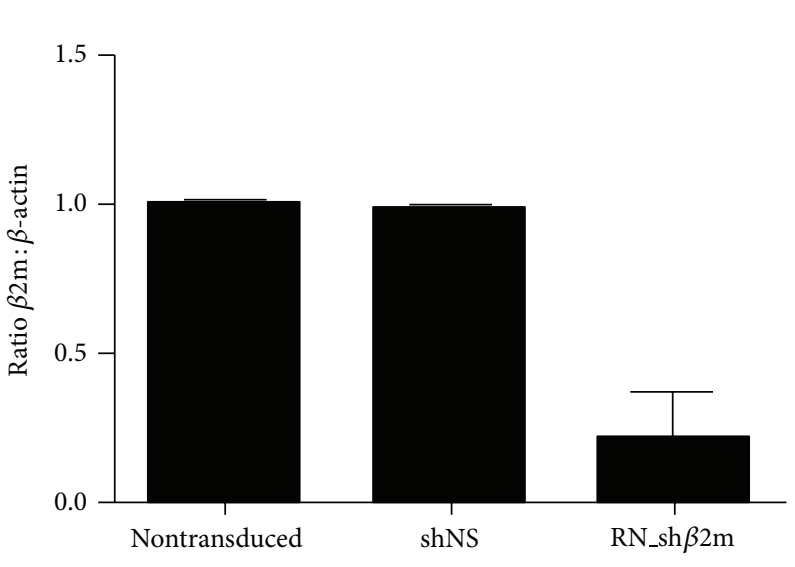

(a)

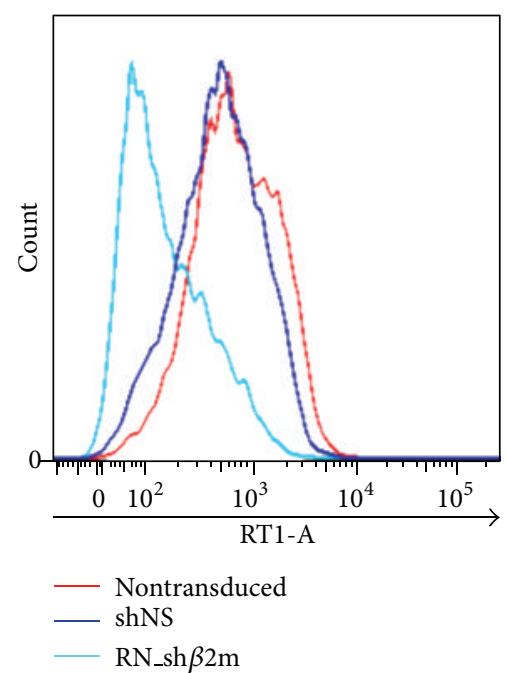

(b)

FIGURE 1: Silencing of RT1-A expression in the LEWis (LEW) rat-derived fibrosarcoma cell line. The fibrosarcoma cell line was transduced using either lentiviral vectors encoding for nonspecific short hairpin RNA (shNS) or a $\beta 2$-microglobulin ( $\beta 2 \mathrm{~m}$-) specific short hairpin RNA (RN_sh $\beta 2 \mathrm{~m}$ ). (a) Relative transcript levels of $\beta 2 \mathrm{~m}$ in fibrosarcoma cells, as determined by real-time PCR 4 days after transduction. (b) Flow cytometry analysis of RT1-A expression on nontransduced fibrosarcoma cells and after the delivery of shNS or RN_sh $\beta 2 \mathrm{~m}$.

2.12. In Vitro Evaluation of NK Cell Activity. RT1 fibroblasts expressing different levels of RT1-A were produced by lentiviral-mediated delivery of shRNAs with different efficiencies in knocking down $\beta 2$-microglobulin. Two shRNA sequences (shRNA_1 and shRNA_2) were used (Table S1). Several RT1 fibrosarcoma cell lines were produced showing reductions on RT1-A expression between $40 \%$ and more than $90 \%$ as measured by flow cytometric analysis. NK cells of 4 rats were isolated from peripheral blood mononuclear cells (PBMCs) by fluorescence-activated cell sorting after cell staining with a phycoerythrin-(PE-) conjugated mouse antirat CD161 (BD Biosciences). Cytotoxic assays were performed by exposing NK cells to fibroblast cells showing different levels of RT1-A expression at an effector: target ratio $5: 1$ for $6 \mathrm{~h}$. Target cell lysis was detected using 7-amino-actinomycin $\mathrm{D}$ (7-AAD). To evaluate the differences between the means of the groups, two-way ANOVA and Bonferroni post tests were performed. Both analyses were carried out using GraphPad Prism v.5.02 (San Diego, CA). Statistically significant differences are shown with asterisks $\left({ }^{*} P<0.05,{ }^{* *} P<0.01\right.$, *** $P<0.001)$.

\section{Results}

3.1. Silencing of RT1-A Expression. Rat LEW-derived RT1 fibrosarcoma cells expressing firefly luciferase were transduced with either a lentiviral vector encoding for nonspecific shRNA or $\beta 2 \mathrm{~m}$-specific shRNA (Table S1). This cell line is a susceptible target to $\mathrm{T}$ and $\mathrm{NK}$ cell activity, and it is of great advantage in transplant rejection models. A transduction efficiency of $95 \pm 4 \%$ was achieved. Transduction of RT1 fibroblasts with the vector coding for $\beta 2 \mathrm{~m}$-specific shRNA (RN_sh $\beta 2 \mathrm{~m}$ ) caused an $82 \%$ reduction of $\beta 2 \mathrm{~m}$ mRNA in comparison to nonmodified cells. This resulted in an up to $80 \pm 7 \%$ decrease in RT1-A protein expression on the cell surface. In comparison to nontransduced cells, delivery of nonspecific shRNA (shNS) into RT1 fibroblasts did not significantly affect $\beta 2 \mathrm{~m}$ mRNA levels. Fibroblasts expressing shNS showed $98 \%$ of the RT1-A expression measured on nonmodified cells (Figure 1).

3.2. Evaluation of Cell Engraftment and Proliferative Capacity. The engraftment and proliferative capacities of RT1-Aexpressing versus RT1-A-silenced fibrosarcoma cells were evaluated by palpation after syngeneic and allogeneic transplantation of the cells (Figure 2(a)). $\beta 2$-microglobulin transcript levels remained downregulated as detected at weeks 2 and 8 after cell transplantation (ratio $\beta 2 \mathrm{~m}$ : $\beta$-actin week 2: $0.20 \pm 0.07$; week 8: $0.21 \pm 0.06)$ accordingly to the levels measured immediately before transplantation $(0.19 \pm$ 0.05). Similarly, RT1-A expression levels remained silenced after transplantation (MFI week 2: $459.7 \pm 107.5$, week 8: $513.5 \pm 133.0)$ as compared to RT1-A expression level detected prior to transplantation $(552.2 \pm 169.1)$ (Figures 2 (b) and 2(c)). Tumor growth was measured weekly for up to eight weeks. Tumor volumes were measured as mean \pm standard deviation $\left(\mathrm{cm}^{3}\right)$ in eight animals per group. Two weeks after transplantation into LEW rats (syngeneic model), tumor volumes of $2.77 \pm 2.18 \mathrm{~cm}^{3}$ and $2.70 \pm 1.56 \mathrm{~cm}^{3}$ were detected in the animals injected with RT1-A-expressing and -silenced cells, respectively. The animals were sacrificed at that time to prevent pain and morbidity due to excessive tumor growth. Tumor volumes were much smaller after allogeneic transplantation into LEW.1W rats. In these animals, mean tumor volumes of $1.37 \pm 1.34 \mathrm{~cm}^{3}$ and $1.37 \pm 0.73 \mathrm{~cm}^{3}$ were measured two weeks after transplantation of RT1-A-expressing or silenced fibrosarcoma cells. No tumor was detectable 


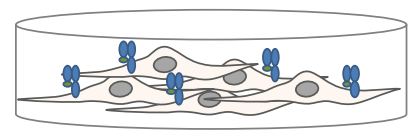

RT1-A ${ }^{1}, \mathrm{RT} 1-\mathrm{B} / \mathrm{D}^{1}, \mathrm{RT} 1-\mathrm{C}^{\mathrm{l}}$

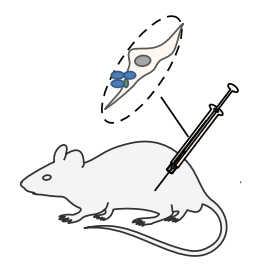

LEW

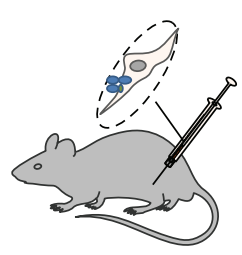

LEW.1W

RT1-A ${ }^{\mathrm{u}}, \mathrm{RT} 1-\mathrm{B} / \mathrm{D}^{\mathrm{u}}, \mathrm{RT} 1-\mathrm{C}^{\mathrm{u}}$

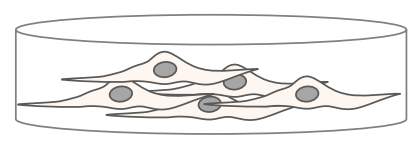

RT1-A (silenced), RT1-B/D ${ }^{1}, \mathrm{RT} 1-\mathrm{C}^{1}$

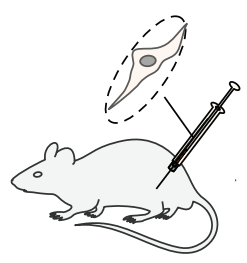

LEW

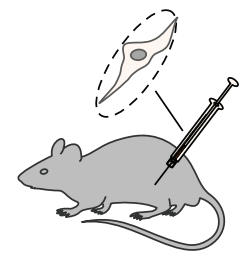

LEW.1W

(a)

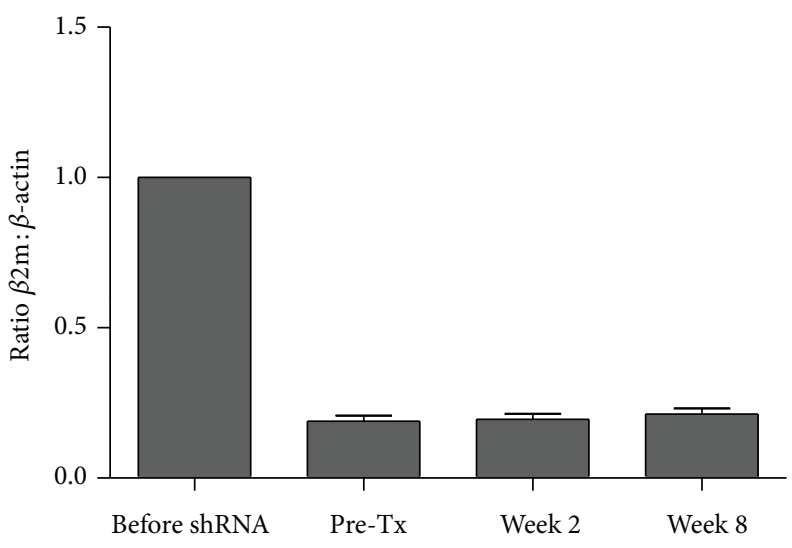

(b)

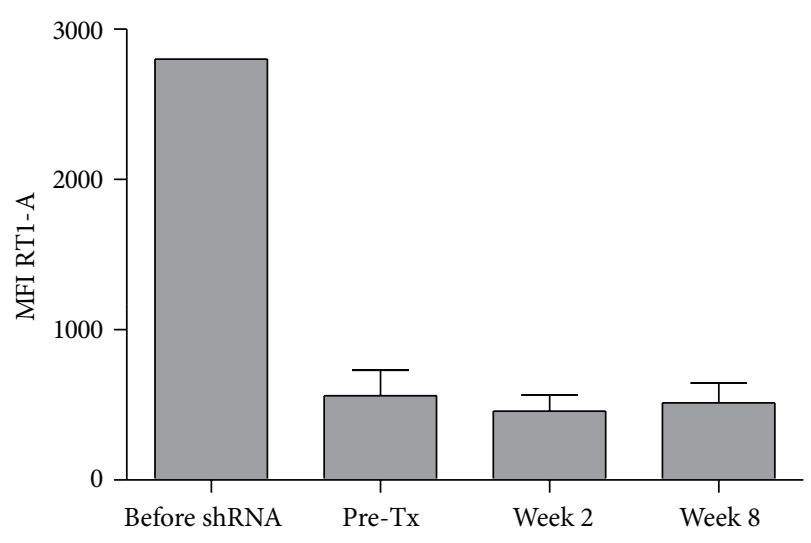

(c)

FIGURE 2: Syngeneic and allogeneic transplantation models of stably MHC class I-silenced cells. (a) Fibrosarcoma cells expressing RT1A molecules and control shRNA (shNS) or RT1-A-silenced fibrosarcoma cells derived from LEWis (LEW) rats after delivery of $\beta 2$ microglobulin-specific shRNA (RN_sh $\beta 2 \mathrm{~m}$ ) were injected subcutaneously into the left hind leg of LEW rats (haplotype-matched setting) or LEW.1W rats (haplotype-mismatched setting). Histograms depict $\beta 2$-microglobulin levels measured by real-time PCR (b) and MHC class I expression represented as mean fluorescence intensity (MFI) (c) on the fibroblast cells before the delivery of the shRNAs, immediately before transplantation, and two and eight weeks after transplantation.

three weeks after transplantation in LEW.1W rats receiving RT1-A-expressing fibrosarcoma cells. In those receiving RT1-A-silenced cells, the mean tumor volume increased to $3.58 \pm 2.32 \mathrm{~cm}^{3}$ three weeks after injection and then decreased to $2.89 \pm 2.63 \mathrm{~cm}^{3}$ four weeks after injection and to $1.88 \pm$ $1.36 \mathrm{~cm}^{3}$ five weeks after injection. Similar volumes were still detectable eight weeks after transplantation (Figure 3). In vivo imaging analyses of the transplanted cells confirmed these results (Figure 4). All animals were sacrificed at that time point.

3.3. Detection of T-Cell and NK Cell Infiltration. Parenchymal leukocyte infiltration after organ transplantation is indicative of organ rejection [27, 28]. Here, immunofluorescence staining was performed to detect the presence of CD4+ and CD8+ T cells. As MHC class I-deficient cells may be targets for NK cells, we also tested for the presence of NK cells in the tissue. CD4+ and CD8+ T-cell infiltration into tissues generated by transplanting RT1-A-expressing cells transplanted into LEW.1W rats was significantly higher than that in tissues generated with RT1-A-silenced cells (Figures 5(a), 5(b), 5(d), 5(e), 5(g), 5(h), 5(j), and 5(k)). No abnormal NK cell infiltration was observed in tissues generated by transplanting RT1-A-silenced cells in an allogeneic setting (Figures 5(c), 5(f), 5(i), and 5(l)).

3.4. Cytokine Secretion Profile in Rat Serum after Cell Transplantation. Cytokines are important signaling molecules during rejection episodes $[29,30]$. Therefore, we measured cytokine levels in the plasma of rats transplanted with syngeneic or allogeneic fibroblasts with intact or silenced $\beta 2 \mathrm{~m}$ expression. Allogeneic transplantation of RT1-A-expressing fibroblasts in LEW.1W rats induced significantly higher IL-1 $\alpha$ levels $(678.3 \pm 345.4 \mathrm{pg} / \mathrm{mL}, P<0.001)$ than the syngeneic transplantation into LEW rats $(7.0 \pm 3.2)$. Nevertheless, allogeneic transplantation of $\beta 2 \mathrm{~m}$-silenced fibroblasts led to a nonsignificant increase in IL- $\alpha(36.2 \pm 29.8 \mathrm{pg} / \mathrm{mL})$ in LEW.1W rats compared to the levels measured after 


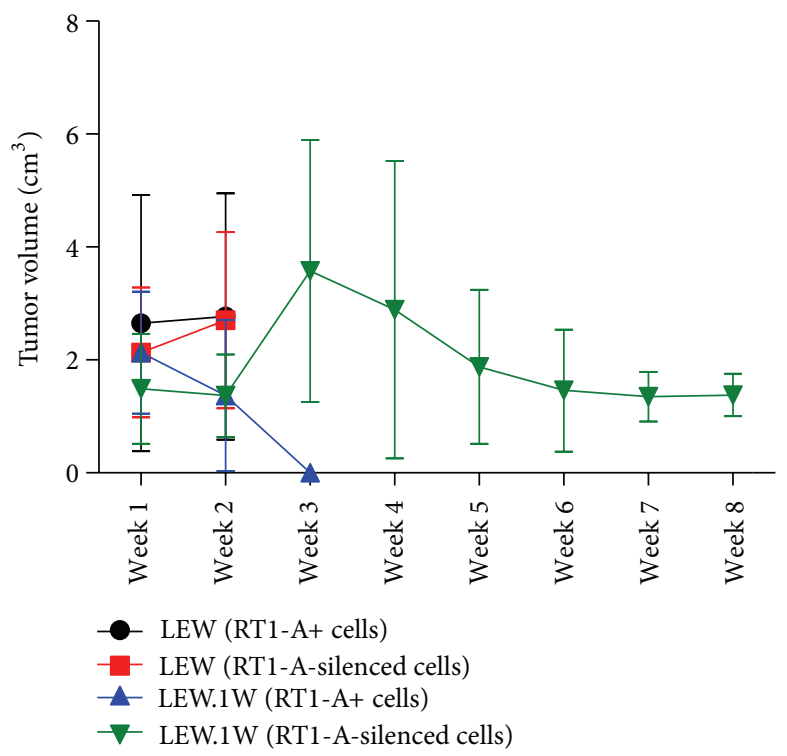

(a)

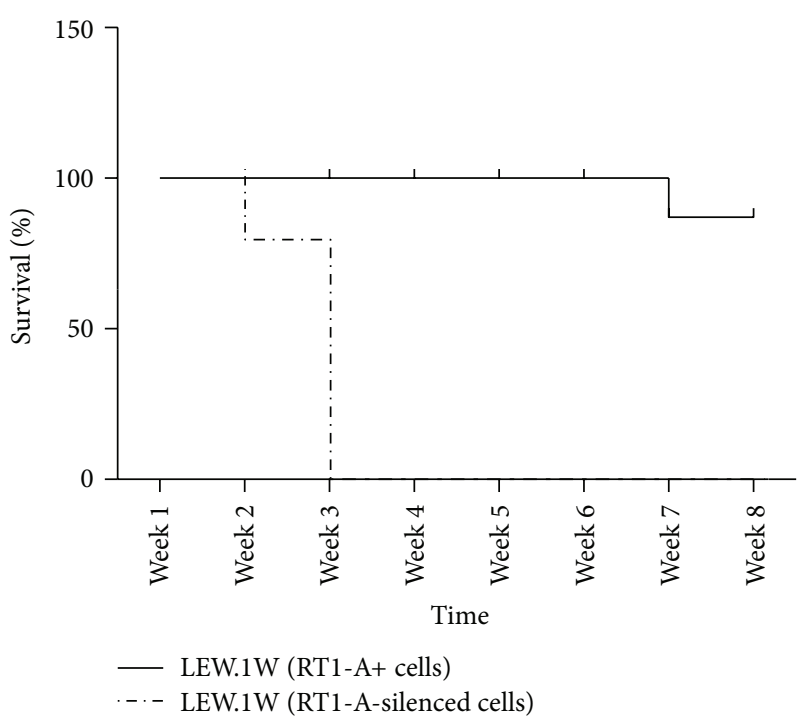

(b)

FIGURE 3: RT1-A silencing promotes graft survival in allogeneic transplantation. (a) Mean tumor volume. (b) Percentage of graft survival after allogeneic transplantation. Cell engraftment and tumor growth were monitored for 8 weeks after allogeneic transplantation by palpation and bioluminescence. All animals in the haplotype-matched transplantation groups receiving RT1-A-expressing or RT1-A-silenced cells were sacrificed 2 weeks after transplantation to prevent morbidity due to excessive tumor growth.

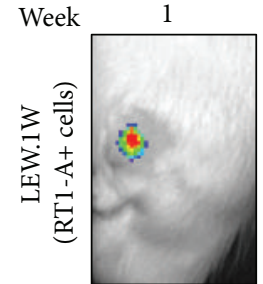

(a)

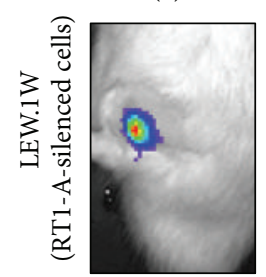

(i)

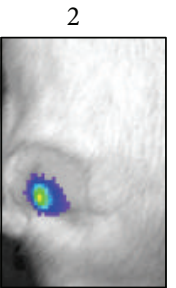

(b)

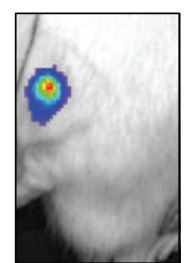

(j)

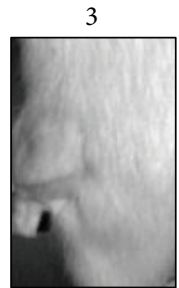

(c)

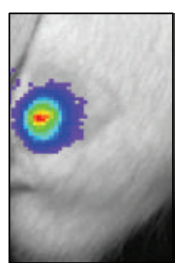

(k)

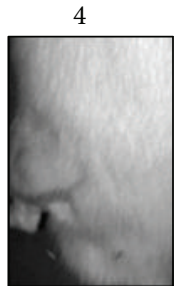

(d)

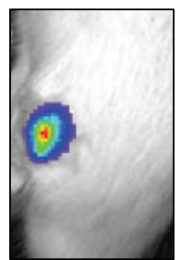

(1)

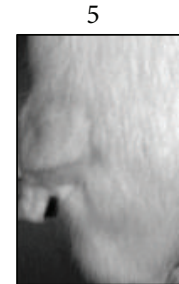

(e)

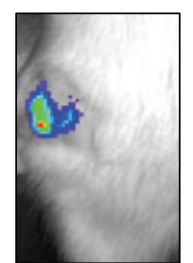

(m)

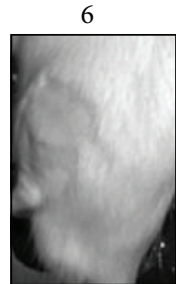

(f)

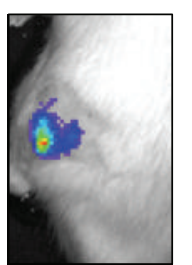

(n)

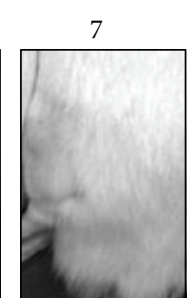

(g)

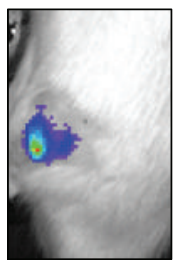

(o)

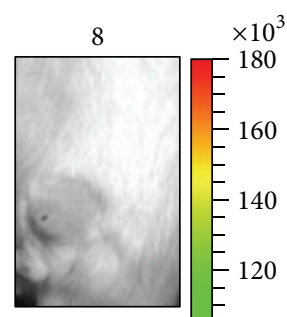

(h)

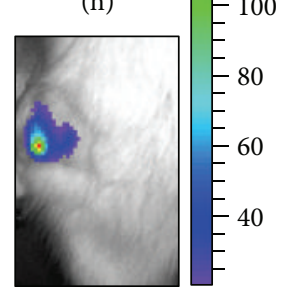

(p)

FIGURE 4: In vivo engraftment and viability of RT1-A-expressing or -silenced LEW rat-derived fibroblasts after subcutaneous injection into LEW.1W rats. In vivo optical imaging analysis of the injection site in representative LEW.1W rats. The reference color bar indicates high levels of bioluminescence in red and low levels in blue.

syngeneic transplantation (IL- $1 \alpha: 7.2 \pm 3.7 \mathrm{pg} / \mathrm{mL})$. Similarly, a significant increase in IL- $1 \beta(80.7 \pm 20.3 \mathrm{pg} / \mathrm{mL}, P<0.01)$ was detected after allogeneic transplantation of fully RT1A-expressing fibroblasts. Allogeneic transplantation of $\beta 2 \mathrm{~m}$ silenced fibroblasts into LEW.1W rats caused a slight increase in IL- $1 \beta$ secretion $(22.7 \pm 10.3 \mathrm{pg} / \mathrm{mL})$ relative to levels measured after syngeneic transplantation to LEW rats $(15.5 \pm$ $5.0 \mathrm{pg} / \mathrm{mL}$ ). Allogeneic transplantation of RT1-A-expressing fibroblasts into LEW.1W rats resulted in significantly higher
IL-6 levels than syngeneic transplantation of these cells into LEW rats $(789.6 \pm 111.2$ versus $138.9 \pm 58.7 \mathrm{pg} / \mathrm{mL} ; P<0.001)$. However, allogeneic transplantation of $\beta 2 \mathrm{~m}$-silenced fibroblasts and syngeneic transplantation of RT1-A-expressing or -silenced cells resulted in comparable IL-6 expression levels $(159.8 \pm 123$ versus $126.2 \pm 73.4 \mathrm{pg} / \mathrm{mL})$. Significantly higher IFN- $\gamma$ secretion $(130.9 \pm 80.3 \mathrm{pg} / \mathrm{mL}, P<0.001)$ was detected after allogeneic transplantation of RT1-A-expressing cells than after syngeneic transplantation $(23.2 \pm 10.4 \mathrm{pg} / \mathrm{mL})$. 


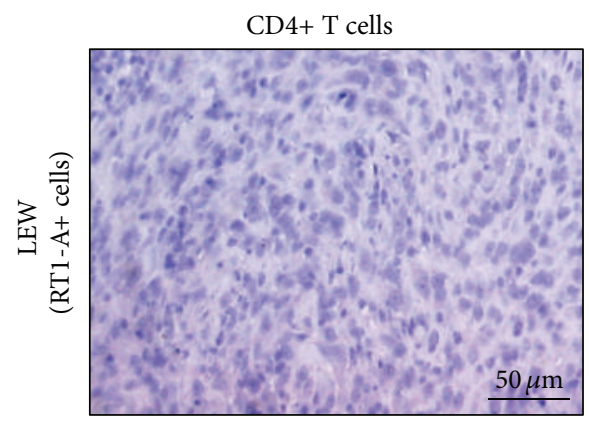

(a)

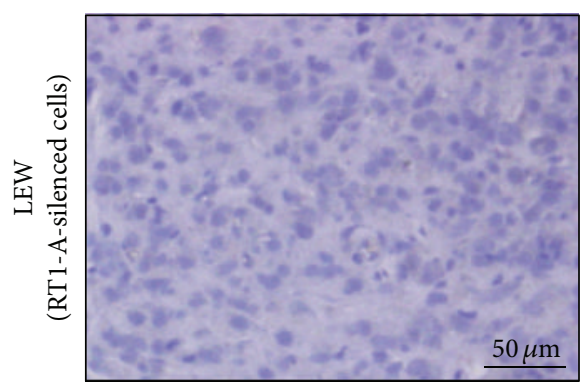

(d)

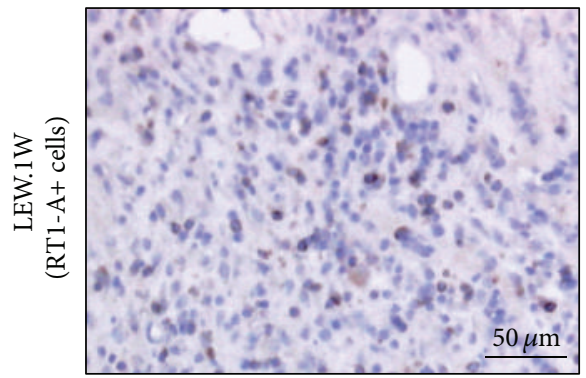

(g)

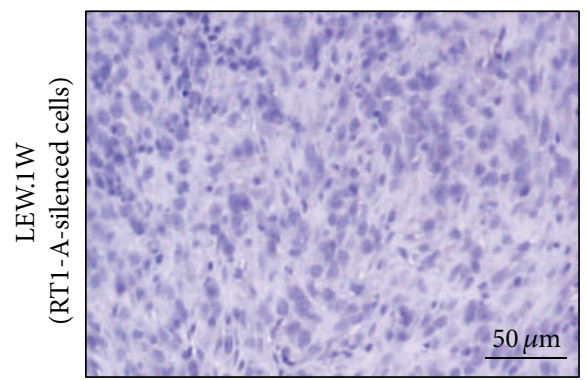

(j)

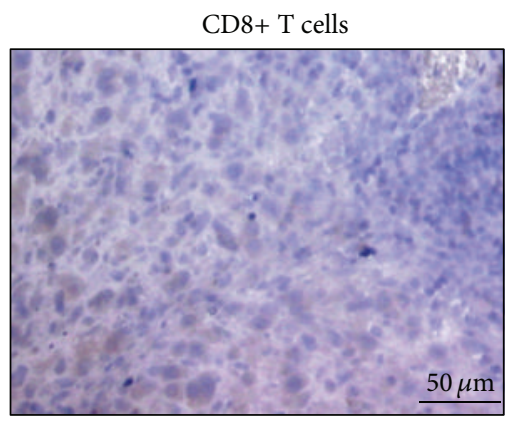

(b)

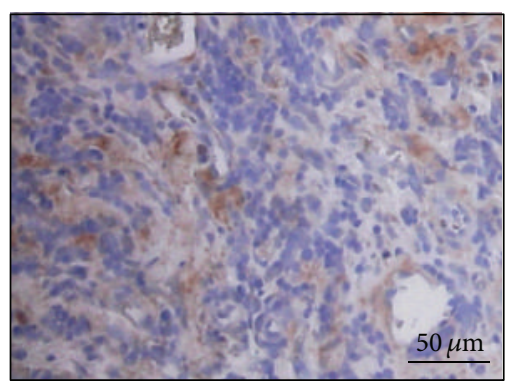

(e)

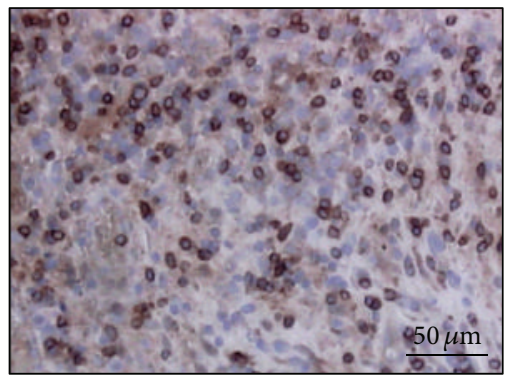

(h)

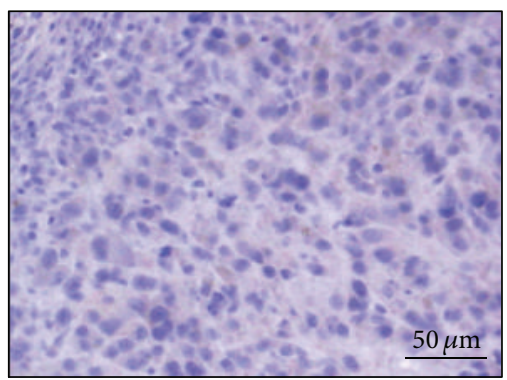

(k)

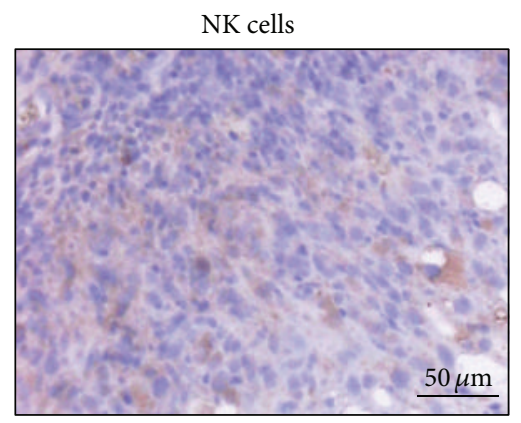

(c)

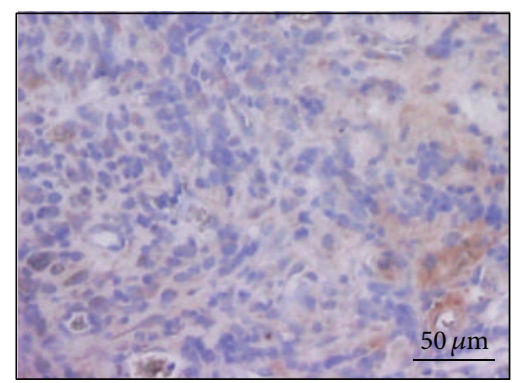

(f)

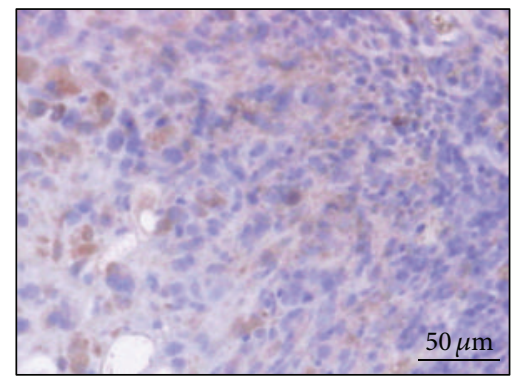

(i)

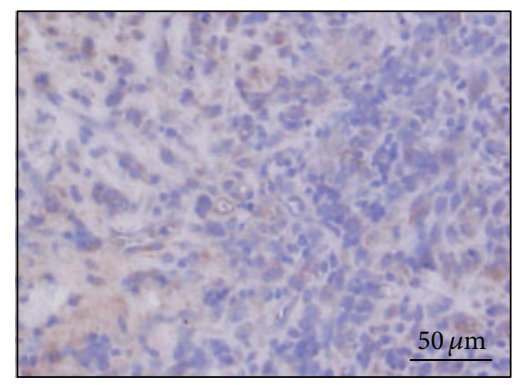

(1)

FIGURE 5: Analysis of tissue infiltration by lymphocytes. T cells and natural killer (NK) cells infiltrated tissues derived from LEW rat cells $\left(\mathrm{RT1}-\mathrm{A}^{\mathrm{l}}\right)$ after transplantation into LEW and LEW.1W (RT1- $\left.{ }^{\mathrm{u}}\right)$ rats. Scale bar $=50 \mu \mathrm{m}$.

Interestingly, injection of RT1-A-silenced cells into allogeneic recipients induced significantly lower secretion of IFN- $\gamma$ $(32.1 \pm 6.4 \mathrm{pg} / \mathrm{mL}, P<0.001)$. Similar results were observed for TNF- $\alpha$ secretion. Significantly higher TNF- $\alpha$ levels (45.9 $\pm 18.2 \mathrm{pg} / \mathrm{mL}, P<0.001)$ were detected after transplantation of RT1-A-expressing cells into LEW.1W rats versus LEW rats $(8.0 \pm 1.5 \mathrm{pg} / \mathrm{mL})$. However, serum TNF- $\alpha$ levels were significantly lower $(10.3 \pm 5.2 \mathrm{pg} / \mathrm{mL}, P<0.001)$ after allogeneic transplantation of RT1-A-silenced cells (Table 1).
This data suggests that silencing of MHC class I expression in grafted cells does not induce a cytokine storm that might contribute to amplify the immune response against cells from allogeneic sources.

3.5. T-Cell Proliferation Assay. Proliferative T-cell alloresponses in mixed lymphocyte reactions indicate a high susceptibility for transplant rejection and are predictive for 
TABLE 1: Cytokine secretion profile.

\begin{tabular}{lcccc}
\hline Analytes pg/mL & LEW (RT1-A cells) & LEW (RT1-A-silenced cells) & LEW.1W (RT1-A cells) & LEW.1W (RT1-A-silenced cells) \\
\hline IL-1 $\alpha$ & $17.0 \pm 5.9$ & $15.5 \pm 5.0$ & $80.7 \pm 20.3^{* * *}$ & $22.7 \pm 10.3$ \\
IL-1 $\beta$ & $23.2 \pm 10.4$ & $27.8 \pm 9.2$ & $130.9 \pm 80.3^{* * *}$ & $32.1 \pm 6.4$ \\
IL-6 & $8.0 \pm 1.5$ & $8.3 \pm 2.1$ & $45.9 \pm 18.2^{* * *}$ & $10.3 \pm 5.2$ \\
TNF- $\alpha$ & $7.0 \pm 3.2$ & $7.2 \pm 3.7$ & $678.3 \pm 345.4^{* * *}$ & $36.2 \pm 29.8$ \\
IFN- $\gamma$ & $138.9 \pm 58.7$ & $126.2 \pm 73.4$ & $789.6 \pm 111.2^{* * *}$ & $159.8 \pm 123.6$ \\
\hline
\end{tabular}

Levels of different cytokines were measured in sera of LEW and LEW.1W rats transplanted with RT1-A-expressing fibroblasts (RT1-A cells) or RT1-A-silenced fibroblasts. Statistically significant differences are indicated by asterisks $\left({ }^{* * *} P<0.001\right)$.

reduced organ survival. The presence of memory $\mathrm{T}$ cells generated de novo after exposure to a first allogeneic graft might constitute an important risk for subsequent organ transplantations [31, 32]. Therefore, we performed proliferation assays to compare the capacities of RT1-A-expressing versus RT1-A-silenced cells to induce the expansion of tissuespecific T-cell clones isolated from LEW or LEW.1W rats transplanted with RT1-A-expressing or -silenced cells. $59.3 \pm$ $21.2 \%$ of T cells derived from LEW.1W rats transplanted with RT1-A-expressing cells proliferated after in vitro exposure to these cells, whereas only $6.4 \pm 2.7 \%$ of T-cells derived from LEW.1W rats transplanted with RT1-A-silenced cells showed to proliferate (Figure 6).

3.6. In Vitro Evaluation of NK Cell Activity. Means of $1.05 \% \pm$ 0.86 and $3.5 \% \pm 1.33$ of target cell lysis were achieved when $40-50 \%$ and $50-70 \%$ RT1-A silenced fibrosarcoma cells were used, respectively. A maximum of $5 \%$ of fibroblasts silenced by up to $90 \%$ for RT1-A expression were lysed by NK cells. The killing rates were significantly higher when fibrosarcoma cells expressing less than $10 \%$ of the normal RT1-A expression were used as target cells $(34.94 \% \pm 11.62, P<0.001)$. Hence, for the allogeneic transplantation experiments we have used a fibrosarcoma cell line with a residual RT1-A expression of more than $10 \%$ as compared to the nonmodified cells or shNS-producing cells to prevent rejection due to NK cell activation (Figure 7).

\section{Discussion}

The variability of MHC genes is a major obstacle to allogeneic transplantation. Several studies have demonstrated a positive correlation between the number of donor-recipient MHC genes mismatches and the rate of rejection episodes after allogeneic transplantation. Previously, we demonstrated the feasibility of permanently silencing HLA class I and II expression in several human cell types. Other in vitro studies have shown that HLA-silenced cells are not only able to prevent the initiation of specific immune responses and are also protected from antibody- and cell-mediated cytotoxicity. Moreover, in vitro analyses have shown that functional properties of HLA-silenced cells were comparable to those of nonengineered cells [21-23]. In this study, we used an allogeneic transplantation model in rats to investigate whether MHC class I-silenced cells are able to engraft, proliferate, and survive in vivo. Regenerative medicine has opened up avenues for the development of novel therapeutic approaches to treat degenerative diseases and organ failure diseases, the incidence of which has risen significantly in the last few years. Human ESCs or iPS cells have gained much attention for their capacity to differentiate into cell types potentially involved in the pathogenesis of specific diseases $[33,34]$. In fact, this strategy allows for the generation of disease-specific iPS cell lines for diseases such as Huntington's disease, congenital dyskeratosis, and fragile $\mathrm{X}$ syndrome [3, $35,36]$. However, MHC incompatibility remains a major hurdle for regenerative medicine as most of the developed products are of allogeneic origin.

This study showed that MHC class I-silenced cells are capable of escaping the immune response by preventing the activation of effector cells. Thus, molecular silencing of MHC class I expression may represent a new tool to facilitate the use of off-the-shelf products in regenerative medicine without the need for immunosuppression. Silencing of MHC expression may not only overcome the compatibility-related problems of MHC mismatch but also prevent the presentation of antigens derived from other polymorphic proteins (minor histocompatibility antigens). In our model, we have used a fibroblast cell line susceptible to T- and NK-cell activity. Here, transplantation of MHC class I-expressing cells using the haplotype-mismatched transplantation model resulted in complete cell loss in all animals within three weeks. Silencing of MHC class I expression was shown to be stable after cell transplantation during the monitored time period. Only one out of eight LEW.1W rats receiving allogeneic MHC class Isilenced cell transplants developed complete cell rejection six weeks after transplantation. In all other rats, the transplanted RT1-A silenced cells remained detectable until the end of the study (week 8). Although the cause of cell rejection in one of the animals is unclear, the fact that the cells were rejected at a later time may indicate for a chronic rejection mechanism that might have been triggered by MHC class II incompatibility between the donor and recipient cells. Presence of circulating donor-specific antibodies (DSA) has been recognized as a relevant cause of allograft rejection $[37,38]$. IgG levels have been used to monitor the levels of DSA after transplantation [39]. We have evaluated rat IgG plasma levels after transplantation of MHC class I-silenced and nonsilenced cells in an allogeneic manner. We have observed significantly higher IgG plasma levels in animals transplanted with MHC expressing cells in comparison to the IgG levels detected in animals receiving MHC class Isilenced cells (Table S2). In this setting, IgG plasma levels 


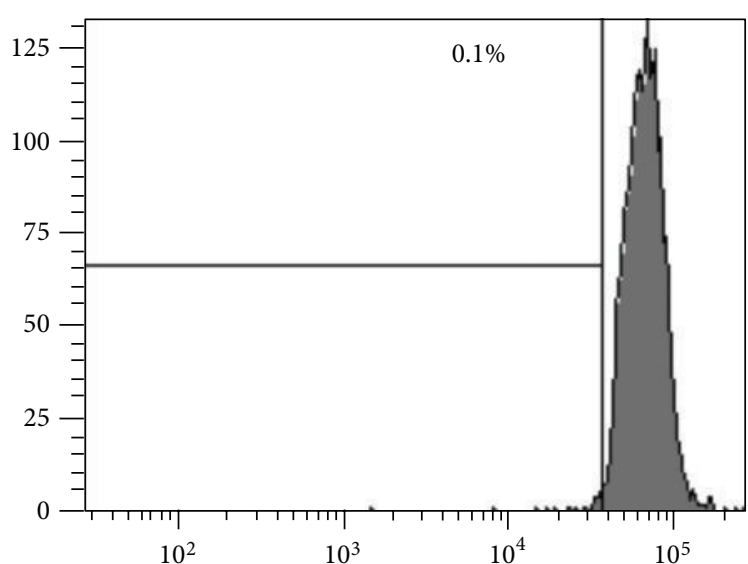

(a)

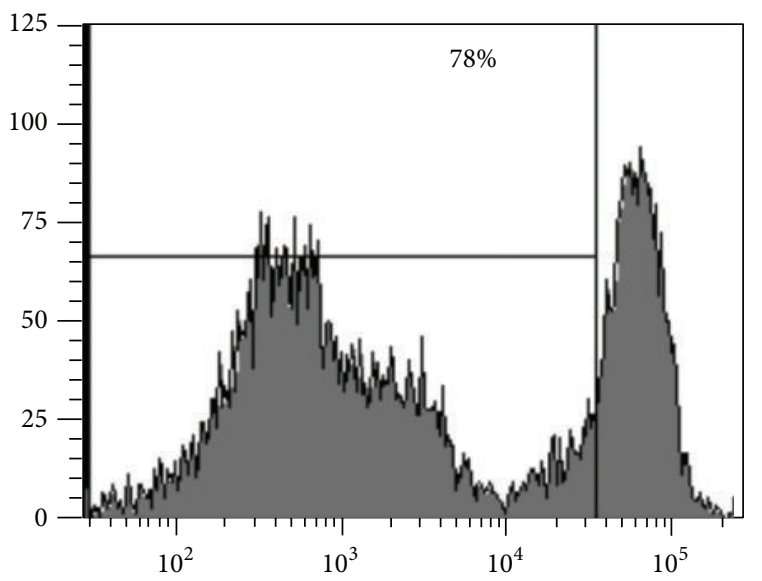

(c)

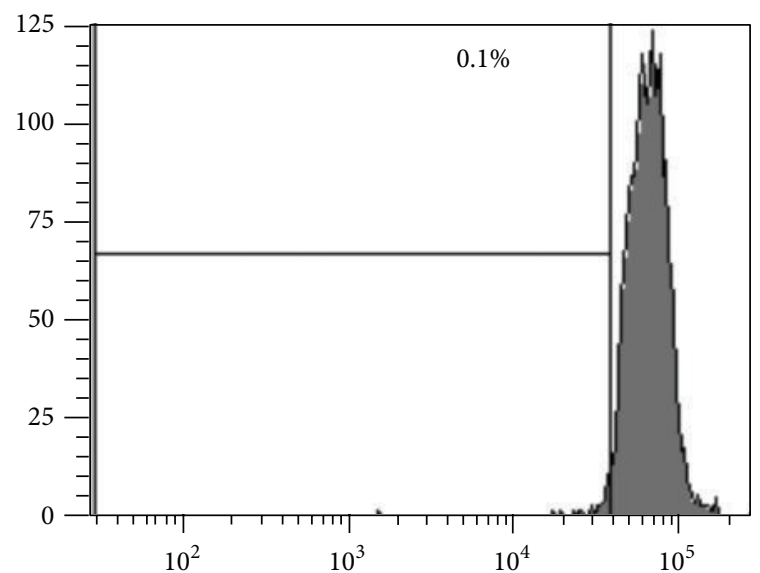

(b)

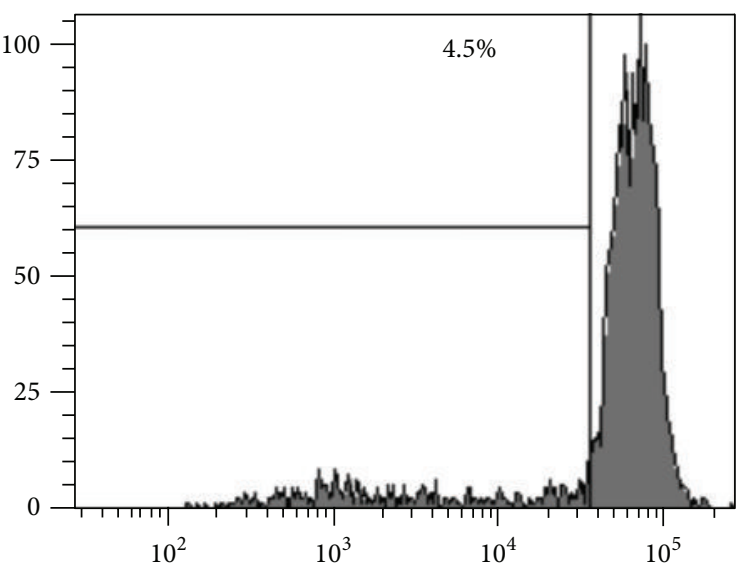

(d)

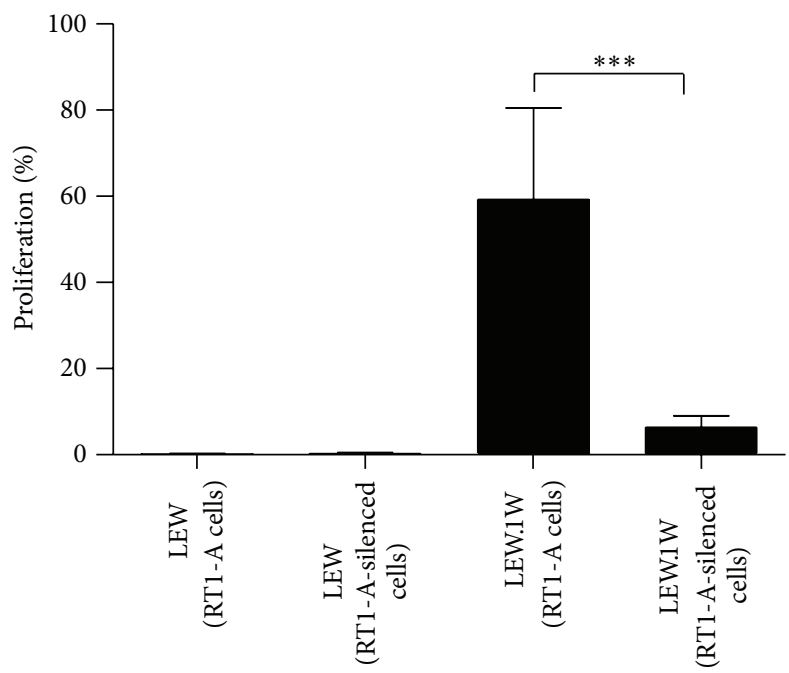

(e)

FIgURE 6: T-cell proliferation assays. Eight weeks after transplantation, T cells were isolated from LEW.1W rats transplanted with either RT1A-expressing or RT1-A-silenced fibroblasts, stained with CFSE, and cocultured in vitro in the presence of RT1-A-expressing fibroblasts for 8 days. ((a)-(d)) Representative experiment for determination of proliferation rates of $\mathrm{T}$ cells isolated from (a) LEW rats transplanted with RT1-A-expressing fibroblasts, (b) LEW rats transplanted with RT1-A-silenced fibroblasts, (c) LEW.1W rats transplanted with RT1-A-expressing fibroblasts, and (d) LEW.1W rats transplanted with RT1-A-silenced fibroblasts. Values are represented as mean and standard deviation of five independent experiments. Two-way ANOVA was used to calculate statistically significant differences between groups. Statistical significance is indicated by asterisks $\left({ }^{*} P<0.05,{ }^{* *} P<0.01,{ }^{* * *} P<0.001\right)$. 


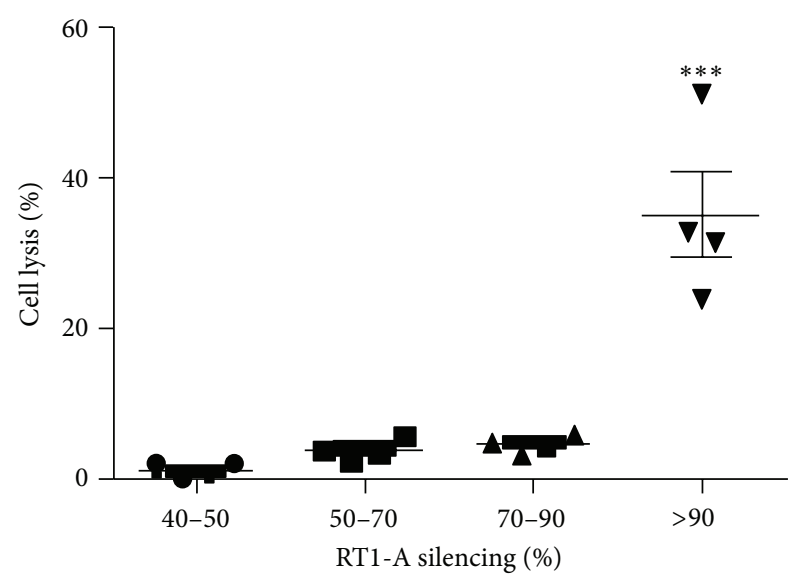

FIGURE 7: Natural killer (NK) cells cytotoxic assays. Freshly isolated NK cells of 4 rats were incubated with fibrosarcoma cells silenced for RT1-A expression at different levels at an effector : target (E: T) ratio $5: 1$ for 6 h. Cell lysis was detected by flow cytometry after staining with 7-amino-actinomycin D. Statistically significant differences are shown with asterisks $\left({ }^{* * *} P<0.001\right)$.

clearly indicate for humoral rejection. However, the animal that lost the MHC class I-silenced cells at week 7 shows much lower IgG plasma levels than the rats that rejected the MHC class I-expressing cells at week 3. In comparison to the animals that did not rejected the MHC class I-silenced cells, only a slight increase in IgG levels was observed in the plasma of the only animal that lost the MHC class I-silenced cells. Hence, it is not possible to conclude that this animal lost the MHC class I-silenced cells only due to a humoral response. Nevertheless, also in this animal silencing MHC expression significantly extended graft survival as the transplanted MHC class I-silenced cells were rejected at a later time point.

Regulation of NK cell activity requires a tight balance between activating and inhibitory signals, which is mediated by distinct classes of receptors on the cell surface. Activating signals are interrupted when inhibitory receptors on NK cells engage MHC class I molecules on target cells [40]. This receptor system is the basis for the "missing self-" activation mechanism enabling NK cells to detect virusinfected cells and cancer cells that express no MHC class I molecules, as proposed by Karre and colleagues [41]. We have determined the residual RT1-A expression level on the fibroblasts required to prevent NK cell lysis. The most efficient shRNA in silencing RT1-A expression without causing the activation of NK cells was selected for the transplantation experiments. Furthermore, we assessed NK cell infiltration in tissues generated from RT1-A silenced cells but observed no abnormal NK cell infiltration after either syngeneic or allogeneic transplantation. The absence of NK cell infiltration in MHC class I-silenced tissues shows that the residual MHC expression might be sufficient to prevent NK cell activation, as we previously demonstrated in vitro [22] and confirmed in this study. The fact that no $\mathrm{T}$ cells were detected and that proinflammatory cytokine levels were comparable to those detected after haplotype-matched transplantation also suggests a lower recruitment of effector cells to the graft.
Memory is a major characteristic of the adaptive immune system. Environmental antigens, pathogens, or alloantigens can trigger the activation of adaptive immune responses of naïve $\mathrm{T}$ cells upon T-cell receptor (TCR) interaction with specific complexes formed by antigens loaded into MHC molecules and presented by antigen-presenting cells (APCs). Antigen stimulation together with a costimulatory signal supplied by APCs triggers proliferation and subsequent differentiation of naïve $\mathrm{T}$ cells into effector $\mathrm{T}$ cells. Effector $\mathrm{T}$ cells secrete several cytokines and chemokines that recruit and activate auxiliary immune cells (e.g., B cells) for antibody production and macrophages for antigen clearance. It is not completely clear how many cell divisions cytotoxic $\mathrm{T}$ cells must undergo to acquire effector function. However, it is known that while naïve $\mathrm{T}$ cells differentiate into cytotoxic effector cells and they become capable of producing proinflammatory cytokines such as IFN- $\gamma$ and TNF- $\alpha$ and cytotoxic molecules such as perforin and granzymes. In accordance with these observations, we detected a significant increase in serum cytokines (e.g., TNF- $\alpha$ and IFN- $\gamma$ ) in rats receiving allogeneic RT1-A-expressing cells in comparison to those treated with syngeneic or allogeneic RT1-A-silenced cells. Nonsilenced RT1-A haplotype-mismatched transplantation also resulted in a significant increase in IL- $1 \alpha$ and IL$1 \beta$ levels. The observed augmentation of IL-1 cytokine levels in animals during graft rejection is in accordance with the observations of others. Several studies have demonstrated that high levels of IL-1 $\alpha$ and IL-1 $\beta$ are associated with Tcell infiltration $[42,43]$. In this study, T-cell infiltration of the graft was positively associated with increased IL- $1 \alpha$ and IL-1 $\beta$ levels. Most activated or effector T cells have a short lifetime, but a small percentage of activated cells persist and develop into long-lived memory $\mathrm{T}$ cells, which have the capacity to mediate potent recall responses when reactivated by antigens $[44,45]$. In the present study, Tcell proliferation rates in rats transplanted with RT1-Asilenced cells were significantly lower after in vitro exposure to RT1-A-expressing cells than those in rats transplanted with RT1-A expressing cells. This observation indicates the presence of memory T cells in the animals receiving RT1-Aexpressing grafts due to their faster capacity for recognition and proliferation after reexposure to the antigen in vitro. Conversely, the low proliferation rates exhibited by $\mathrm{T}$ cells derived from animals transplanted with RT1-A-silenced cells indicate that they had not been primed for the mismatched antigens.

In conclusion, the results of this study indicate that MHC class I silencing significantly prolongs graft survival following allogeneic transplantation. This effect is mainly due to the fact that MHC class I-silenced cells are not recognized by the recipient's immune system and therefore do not induce its activation. Silencing of MHC class I gene expression in grafted cells does not induce tolerance but "hides" the graft from the immune system. Silencing of MHC expression on transplanted cells, tissues, or organs has the potential to revolutionize the field of transplantation and to facilitate the re-expoadministration of many cell-based products developed for regenerative medicine purposes. 


\section{Conflict of Interests}

The authors have no conflict of interests to declare.

\section{Acknowledgments}

The authors are grateful to Jana Zenk, Elena Wiebe and Kirsten Elger for their excellent technical assistance. This work was supported by the German Research Foundation (REBIRTH, EXC 62).

\section{References}

[1] G. Orlando, P. Baptista, M. Birchall et al., "Regenerative medicine as applied to solid organ transplantation: current status and future challenges," Transplant International, vol. 24, no. 3, pp. 223-232, 2011.

[2] A. S. Boyd and P. J. Fairchild, "Approaches for immunological tolerance induction to stem cell-derived cell replacement therapies," Expert Review of Clinical Immunology, vol. 6, no. 3, pp. 435-448, 2010.

[3] I. Park, N. Arora, H. Huo et al., "Disease-specific induced pluripotent stem cells," Cell, vol. 134, no. 5, pp. 877-886, 2008.

[4] D. Smith, "Commercialization challenges associated with induced pluripotent stem cell-based products," Regenerative Medicine, vol. 5, no. 4, pp. 593-603, 2010.

[5] T. Zhao, Z. Zhang, Z. Rong, and Y. Xu, "Immunogenicity of induced pluripotent stem cells," Nature, vol. 474, no. 7350, pp. 212-215, 2011.

[6] M. A. Fernandez-Vina, J. P. Klein, M. Haagenson et al., "Multiple mismatches at the low expression HLA loci DP, DQ, and DRB3/4/5 associate with adverse outcomes in hematopoietic stem cell transplantation," Blood, vol. 121, no. 22, pp. 4603-4610, 2013.

[7] H. Uchiyama, H. Kayashima, R. Matono et al., "Relevance of HLA compatibility in living donor liver transplantation: the double-edged sword associated with the patient outcome," Clinical Transplantation, vol. 26, no. 5, pp. E522-E529, 2012.

[8] T. A. Binkowski, S. R. Marino, and A. Joachimiak, "Predicting HLA class I non-permissive amino acid residues substitutions," PLoS ONE, vol. 7, no. 8, Article ID e41710, 2012.

[9] S. O. Ciurea, P. F. Thall, X. Wang et al., "Donor-specific anti-HLAAbs and graft failure in matched unrelated donor hematopoietic stem cell transplantation," Blood, vol. 118, no. 22, pp. 5957-5964, 2011.

[10] R. Higgins, D. Lowe, M. Hathaway et al., "Human leukocyte antigen antibody-incompatible renal transplantation: excellent medium-term outcomes with negative cytotoxic crossmatch," Transplantation, vol. 92, no. 8, pp. 900-906, 2011.

[11] C. Susal, D. L. Roelen, G. Fischer et al., "Algorithms for the determination of unacceptable HLA antigen mismatches in kidney transplant recipients," Tissue Antigens, vol. 82, no. 2, pp. 83-92, 2013.

[12] B. L. Davidson and P. B. McCray, "Current prospects for RNA interference-based therapies," Nature Reviews Genetics, vol. 12, no. 5, pp. 329-340, 2011.

[13] S. M. Elbashir, J. Harborth, W. Lendeckel, A. Yalcin, K. Weber, and T. Tuschl, "Duplexes of 21-nucleotide RNAs mediate RNA interference in cultured mammalian cells," Nature, vol. 411, no. 6836, pp. 494-498, 2001.
[14] Y. Gu, W. Hou, C. Xu, S. Li, J. W. K. Shih, and N. Xia, “The enhancement of RNAi against HIV in vitro and in vivo using $\mathrm{H}-2 \mathrm{~K}(\mathrm{k})$ protein as a sorting method," Journal of Virological Methods, vol. 182, no. 1-2, pp. 9-17, 2012.

[15] B. Gillissen, A. Richter, A. Richter et al., "Targeted therapy of the XIAP/proteasome pathway overcomes TRAIL-resistance in carcinoma by switching apoptosis signaling to a Bax/Bakindependent "type I" mode," Cell Death and Disease, vol. 4, article e643, 2013.

[16] J. F. Ma, L. Liu, W. J. Yang, L. N. Zang, and Y. M. Xi, "RNAimediated knockdown of relaxin decreases in vitro proliferation and invasiveness of osteosarcoma MG-63 cells by inhibition of MMP-9," European Review for Medical and Pharmacological Sciences, vol. 17, no. 8, pp. 1102-1109, 2013.

[17] C. Raoul, S. D. Barker, and P. Aebischer, "Viral-based modelling and correction of neurodegenerative diseases by RNA interference," Gene Therapy, vol. 13, no. 6, pp. 487-495, 2006.

[18] Y. Hou, L. Xing, S. Fu et al., "Down-regulation of inducible co-stimulator (ICOS) by intravitreal injection of small interfering RNA (siRNA) plasmid suppresses ongoing experimental autoimmune uveoretinitis in rats," Graefe's Archive for Clinical and Experimental Ophthalmology, vol. 247, no. 6, pp. 755-765, 2009.

[19] J. McCaskill, R. Singhania, M. Burgess et al., "Efficient biodistribution and gene silencing in the lung epithelium via intravenous liposomal delivery of siRNA," Molecular TherapyNucleic Acids, vol. 2, article e96, 2013.

[20] J. Presumey, G. Salzano, G. Courties et al., "PLGA microspheres encapsulating siRNA anti-TNF $\alpha$ : efficient RNAi-mediated treatment of arthritic joints," European Journal of Pharmaceutics and Biopharmaceutics, vol. 82, no. 3, pp. 457-464, 2012.

[21] C. Figueiredo, L. Goudeva, P. A. Horn, B. Eiz-Vesper, R. Blasczyk, and A. Seltsam, "Generation of HLA-deficient platelets from hematopoietic progenitor cells," Transfusion, vol. 50, no. 8, pp. 1690-1701, 2010.

[22] C. Figueiredo, A. Seltsam, and R. Blasczyk, "Class-, gene-, and group-specific HLA silencing by lentiviral shRNA delivery," Journal of Molecular Medicine, vol. 84, no. 5, pp. 425-437, 2006.

[23] Y. Jaimes, A. Seltsam, B. Eiz-Vesper, R. Blasczyk, and C. Figueiredo, "Regulation of HLA class II expression prevents allogeneic T-cell responses," Tissue Antigens, vol. 77, no. 1, pp. 36-44, 2011.

[24] L. Riolobos, R. K. Hirata, C. J. Turtle et al., "HLA engineering of human pluripotent stem cells," Molecular Therapy, vol. 21, pp. 1232-1241, 2013.

[25] R. Dressel, L. Walter, and E. Günther, "Genomic and functional aspects of the rat MHC, the RT1 complex," Immunological Reviews, vol. 184, pp. 82-95, 2001.

[26] C. Figueiredo, M. Wittmann, D. Wang et al., "Heat shock protein 70(HSP70) induces cytotoxicity of T-helper cells," Blood, vol. 113, no. 13, pp. 3008-3016, 2009.

[27] G. Einecke, B. Sis, J. Reeve et al., "Antibody-mediated microcirculation injury is the major cause of late kidney transplant failure," The American Journal of Transplantation, vol. 9, no. 11, pp. 2520-2531, 2009.

[28] D. Ishii, A. D. Schenk, S. Baba, and R. L. Fairchild, "Role of $\mathrm{TNF} \alpha$ in early chemokine production and leukocyte infiltration into heart allografts," The American Journal of Transplantation, vol. 10, no. 1, pp. 59-68, 2010.

[29] H. Wang, Q. Guan, Z. Lan et al., "Prolonged renal allograft survival by donor interleukin-6 deficiency: association with 
decreased alloantibodies and increased intragraft T regulatory cells," The American Journal of Physiology-Renal Physiology, vol. 302, no. 2, pp. F276-F283, 2012.

[30] M. Hummel, S. M. Kurian, S. Lin et al., "Intragraft TNF receptor signaling contributes to activation of innate and adaptive immunity in a renal allograft model," Transplantation, vol. 87, no. 2, pp. 178-188, 2009.

[31] C. Ashokkumar, R. Shapiro, H. Tan et al., "Allospecific CD154+ T-cytotoxic memory cells identify recipients experiencing acute cellular rejection after renal transplantation," Transplantation, vol. 92, no. 4, pp. 433-438, 2011.

[32] E. Kreijveld, H. J. P. M. Koenen, B. van Cranenbroek, E. van Rijssen, I. Joosten, and L. B. Hilbrands, "Immunological monitoring of renal transplant recipients to predict acute allograft rejection following the discontinuation of tacrolimus," PLOS ONE, vol. 3, no. 7, Article ID e2711, 2008.

[33] R. Maehr, S. Chen, M. Snitow et al., "Generation of pluripotent stem cells from patients with type 1 diabetes," Proceedings of the National Academy of Sciences of the United States of America, vol. 106, no. 37, pp. 15768-15773, 2009.

[34] D. van Hoof, K. A. D’Amour, and M. S. German, "Derivation of insulin-producing cells from human embryonic stem cells," Stem Cell Research, vol. 3, no. 2-3, pp. 73-87, 2009.

[35] S. D. Sheridan, K. M. Theriault, S. A. Reis et al., "Epigenetic characterization of the FMR1 gene and aberrant neurodevelopment in human induced pluripotent stem cell models of fragile X syndrome," PLoS ONE, vol. 6, no. 10, Article ID e26203, 2011.

[36] A. Urbach, O. Bar-Nur, G. Q. Daley, and N. Benvenisty, "Differential modeling of fragile $\mathrm{X}$ syndrome by human embryonic stem cells and induced pluripotent stem cells," Cell Stem Cell, vol. 6, no. 5, pp. 407-411, 2010.

[37] N. Kieran, X. Wang, J. Perkins et al., "Combination of peritubular C4d and transplant glomerulopathy predicts late renal allograft failure," Journal of the American Society of Nephrology, vol. 20, no. 10, pp. 2260-2268, 2009.

[38] F. G. Cosio, J. M. Gloor, S. Sethi, and M. D. Stegall, "Transplant glomerulopathy," The American Journal of Transplantation, vol. 8, no. 3, pp. 492-496, 2008.

[39] N. Kohei, T. Tanabe, S. Horita et al., "Sequential analysis of donor-specific antibodies and pathological findings in acute antibody-mediated rejection in a rat renal transplantation model," Kidney International, 2013.

[40] D. H. Raulet and R. E. Vance, "Self-tolerance of natural killer cells," Nature Reviews Immunology, vol. 6, no. 7, pp. 520-531, 2006.

[41] K. Karre, H. G. Ljunggren, G. Piontek, and R. Kiessling, "Selective rejection of $\mathrm{H}$-2-deficient lymphoma variants suggests alternative immune defence strategy," Nature, vol. 319, no. 6055, pp. 675-678, 1986.

[42] A. A. Wanderer, "Rationale and timeliness for IL- $1 \beta$-targeted therapy to reduce allogeneic organ injury at procurement and to diminish risk of rejection after transplantation," Clinical Transplantation, vol. 24, no. 3, pp. 307-311, 2010.

[43] J. E. Vamvakopoulos, C. J. Taylor, C. Green et al., "Interleukin 1 and chronic rejection: possible genetic links in human heart allografts," The American Journal of Transplantation, vol. 2, no. 1, pp. 76-83, 2002.

[44] D. Masopust, V. Vezys, A. L. Marzo, and L. Lefrançois, "Preferential localization of effector memory cells in nonlymphoid tissue," Science, vol. 291, no. 5512, pp. 2413-2417, 2001.
[45] Y. M. Ortiz, L. F. Arias, C. M. Alvarez, and L. F. Garcia, "Memory phenotype and polyfunctional $\mathrm{T}$ cells in kidney transplant patients," Transplant Immunology, vol. 28, no. 2-3, pp. 127-137, 2013. 


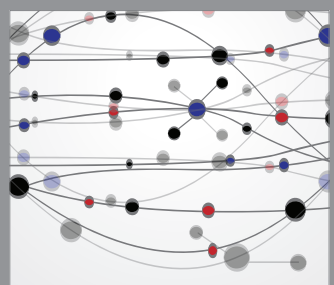

The Scientific World Journal
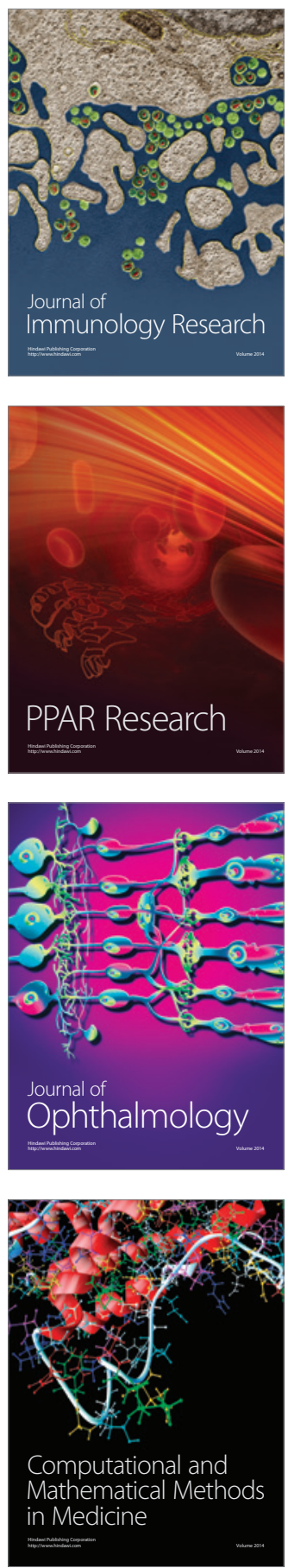

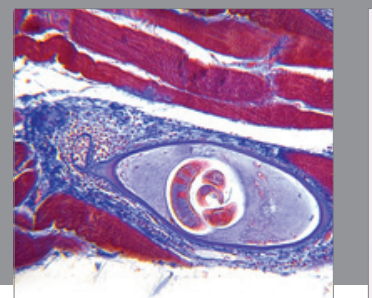

Gastroenterology

Research and Practice
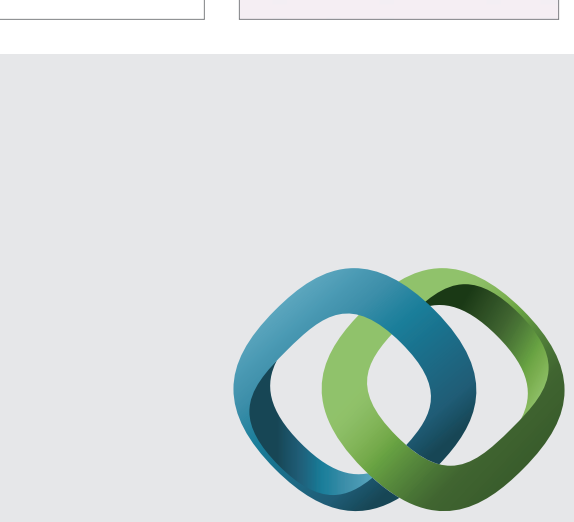

\section{Hindawi}

Submit your manuscripts at

http://www.hindawi.com
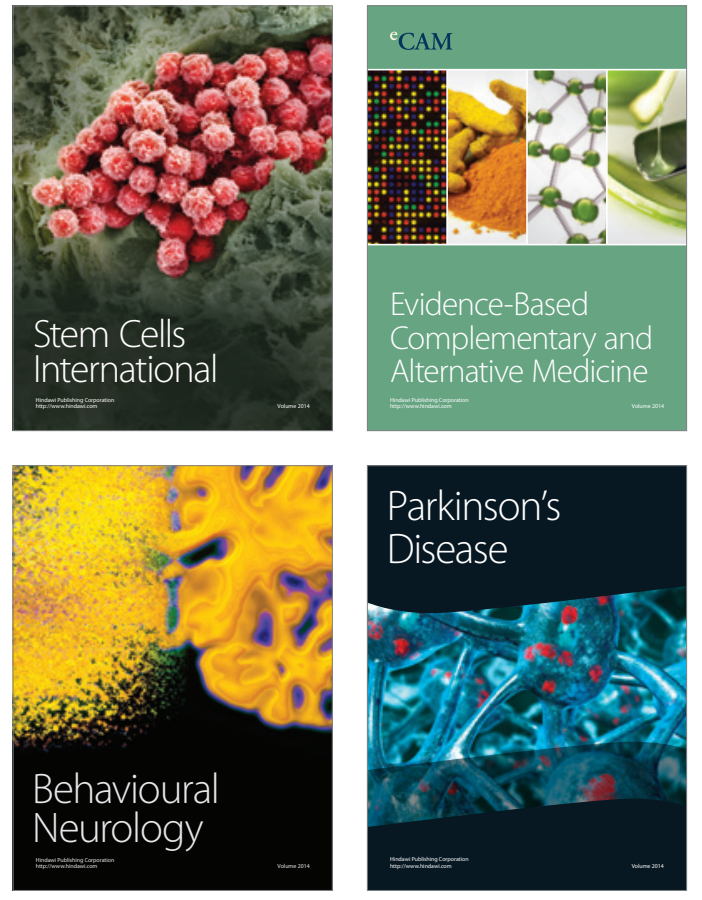
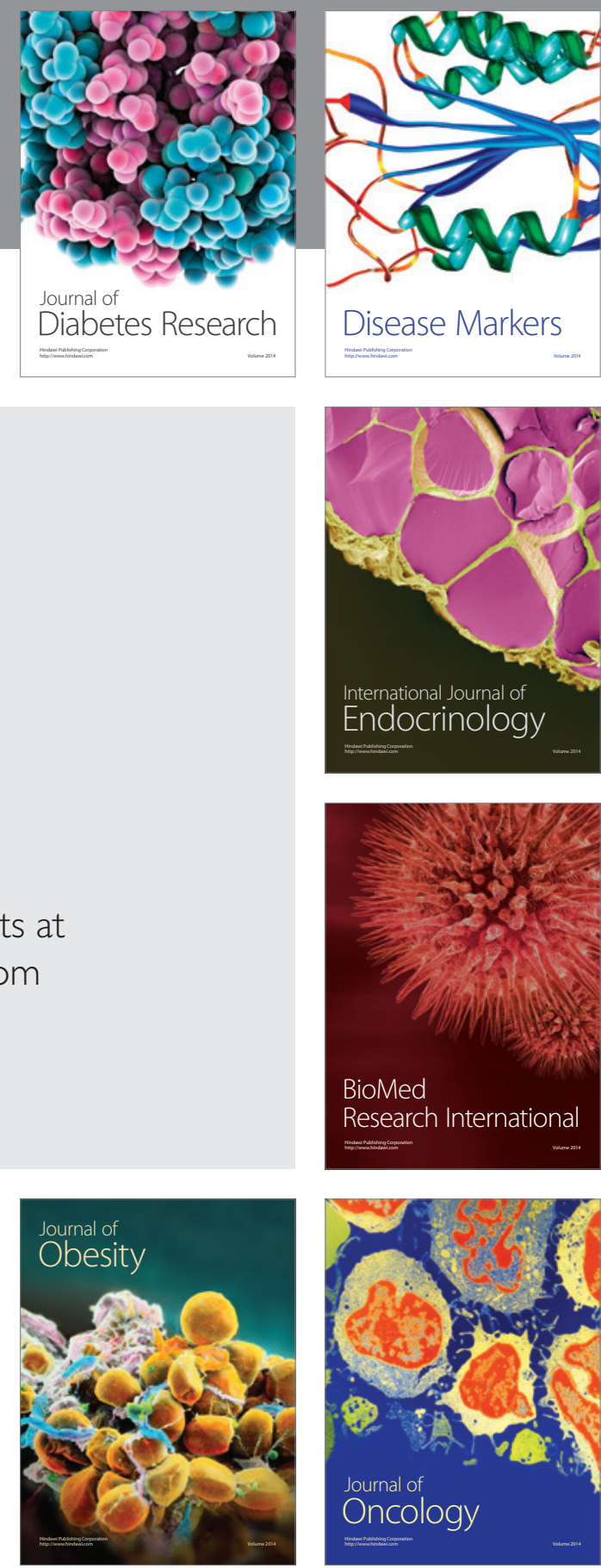

Disease Markers
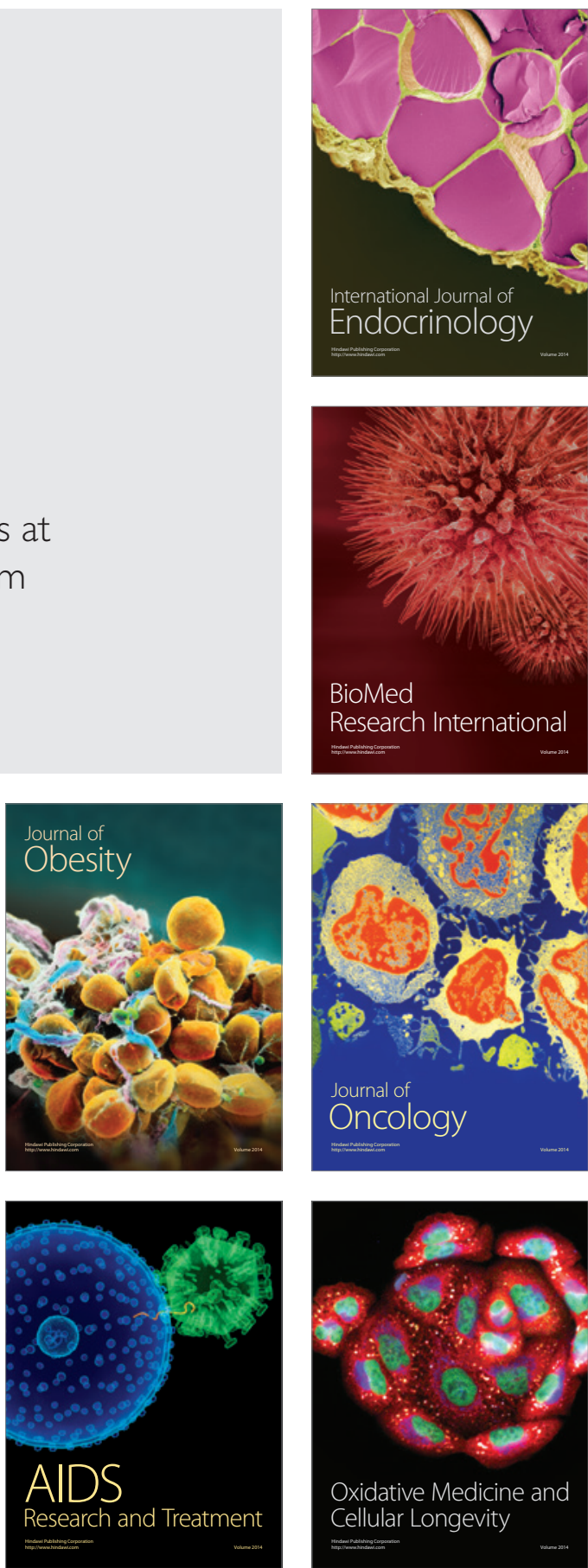